\title{
Assessing the use of Product-Service Systems as a strategy to foster sustainability in an emerging context
}

\author{
Aguinaldo dos Santos ${ }^{a}$, Claudio Pereira Sampaio ${ }^{b}$, Jucelia Salete Giacomini da Silvac ${ }^{c}$ Jairo da Costa Junior ${ }^{d}$ \\ anniversidade Federal do Paraná \\ Universidade Estadual de Londrina \\ Universidade Católica do Rio de Janeiro \\ dDelft University \\ e-mails: asantos@ufpr.br; qddesign@hotmail.com; juceliagiacomini@gmail.com; i.dacostajunior@tudelft.nl
}

\begin{abstract}
This paper presents the results of a research project which have investigated the effectiveness of the contribution of Product-Service Systems (PSS) towards sustainability from a business perspective in an emerging context. The focus of this study is on the implications on the achievement of a "distributed economy". The authors have investigated the issue in three case studies, each representing one of the main typologies of PSS: result-oriented, product-oriented, and service-oriented. The companies that participated in these case studies were from three different business sectors: a packaging manufacturer for the automotive sector, an office space provider, and a major manufacturer of pipes and fittings. The results reported in this paper focus on the three initial phases of the data collection protocol developed in each case study: strategic analysis, exploration of opportunities, and development of the PSS concept. The data collection techniques included semi-structured interviews, system maps, Sustainability Design-Orienting Toolkit (SDO/MEPSS), direct observation, and photography and document analysis. The intracase study analysis was carried out through workshops with the partner companies, followed by cross-case study analysis, with the aim of identifying common patterns. The case studies show that PSS can contribute to expand the involvement of local stakeholders and to the achievement of a higher level of customization to local requirements. They also showed that it is not possible to state that a PSS can result in small, decentralized, and flexible production units. Also, although they expand the net of stakeholders, none of the case studies present an explicit intent to search for synergy with their counterparts in the same business sector, despite the benefit that such strategy could bring to scaling up the PSS concepts. Therefore, the authors conclude that, within a business perspective in an emerging context, there is no direct connection between PSS and the full extent of the "distributed economy" concept.
\end{abstract}

Keywords: product-service system, distributed economy, emerging context.

\section{Introduction}

It could be said that the concept of PSS is a widely present practice among the poor communities in Brazil, though not designed and not necessarily implemented with the sustainability ethos. Their lack of financial means pushed them to adopt consumption practices that includes use-oriented solutions (e.g.: shared laundry machines), result-oriented solutions (e.g.: lunch boxes produced by neighbours) and product-oriented solutions, with a wide range of services to increase the life cycle of products (e.g.: local shoemakers). On the shantytowns, the houses are tiny, requiring a more intensive share of common facilities and more intense interaction with their neighbourhood. PSS practices in such environment occurs more due to necessity than the result of a planned outcome.

In contrast, there is scattered initiatives on sustainable PSS applied within formal business organizations, a situation resulted from a lack of an effective countrywide policy to stimulate the adoption of such concept. Indeed, PSS has not been formally integrated at the "Action Plan for Sustainable Production and Consumption", where the Brazilian government has set its priorities (BRASIL, 2011). Notwithstanding, some of the policies presented on that document could contribute to push PSS forward, such as: the stimulus for the "Creation and Expansion of Business and Markets with Social Inclusion and Less Environmental Impact", "Sustainable Public Procurement", "Innovation and Diffusion of Sustainable Production and Consumption Technologies".

Paradoxically, at the same time that there is such Action Plan, the Brazilian current economic policy focuses on the expansion of product consumption as a main development strategy, with various measures to motivate consumers to buy more goods. Industry has embraced the policy with an expansion of production capacity. As state by 
Stoughton et al. (1998) and Mont (2002), within the industry there is a natural resistance of product-oriented personnel to move beyond point-of-sale since it increases the uncertainty with gains and, at the same time, demands new competencies. Hence, the ambiguous policy set by the State policy is reinforced by conventional business strategies.

In order to change such situation there is a need for governmental support to disseminate knowledge about PSS, including support for projects that demonstrate the positive implications of PSS in changing patterns of consumption and production (MONT; LINDHQVIST, 2003). However, efforts to a more assertive introduction of PSS on the policies and strategies of both private and public sector in emerging contexts such as Brazil suffer from the lack of factual information on its actual benefits for businesses and regions. In this context, the present paper reports the results of a five year investigation on Produce Service Systems (PSS), carried out throughout three consecutive research projects developed at the Design \& Sustainability Research Centre, at Paraná Federal University (NDS/UFPR). The paper attempts to increase our understanding on the way in which interwoven PSS concepts and approaches with the concept of distributed economy.

\section{Product Service Systems (PSS) and Distribute Economies}

\subsection{The PSS concept}

A Product-Service System (PSS) can be defined as an innovation strategy focused on the achievement of satisfaction from the acquisition of physical artefacts to the acquisition of a package of products and services that can jointly fulfil specific client's satisfaction requirements (UNITED..., 2002). From a business perspective PSS can also be seen as merely a profit-seeking innovation strategy, that is, the creation of new ideas with the intention of making more money (POL; VILLE, 2009). It can also be result of lack of financial means among consumers or even the scarcity of materials, pushing the consumer to less resource intensive ways of obtaining satisfaction. Regardless the true intent and motivations PSS offers higher potential to achieve dematerialized ways for obtaining satisfaction when compared to product-based approaches.

The initial associations of products and services have focused on the rapid change from a resource intensive towards a more dematerialized economy, prioritizing the use of services instead of products as the main strategy. Initially the literature used terms such as Intensity Material per Unit Service (MIPS) and Intelligent System Products (ISP) (SCHMIDT-BLEEK, 1993; GIARINI; STAHEL, 1989). These approaches aimed to obtain more efficiency on the utilization of resources with the reduction of intensity of material per unit of service, based on increasing usage performance and the reduction of post-consumer waste.

There is a variety of attempts in the literature to establish PSS categories, with different levels on service intensity, user involvement and product architecture. At NDS/UFPR, in order to enable a dialog with business partners it has been used three categories, based upon the propositions of Tukker (2004):

- Product-oriented PSS: here the business model is mainly oriented around selling products with its usual services (ex: installation, maintenance, warranty) but with added services for life cycle management such as recycling, re-use, and upgrade;

- Use-oriented PSS: here the business model is mainly oriented around the "sale of use", where product can still play a central role but usually its ownership remains with the manufacturer, which is more likely to be motivated to reduce resource consumption throughout the life cycle.

- Result-oriented PSS: the business model here focuses on providing the essential result that brings satisfaction to the final user, leaving to the service provider the decision to set the most efficient technological/managerial arrangement to achieve the targeted satisfaction.

The use of these categories has proved to be quite helpful not only when communicating with stakeholders but also on didactic purposes. However, PSS is in fact a continuum from "pure product" to "pure service, with hybrid possibilities around these categories. Furthermore, the same company that provides a Use-oriented PSS has to be prepared to sell a Product-oriented PSS or even a "Pure Product". The need for an hybrid provision of solutions is reinforced by a previous study carried out by the main author in Brazil in the low income market (SCHÄFER; JAEGER-ERBEN; SANTOS, 2011), where it showed that the rising consumer is still heavily attached the possession of products, as they remain a symbol of social-economic progression. Providing their satisfaction through less resource intensive approaches necessarily requires a transition approach. Vezzoli, Ceschin and Kemp (2008) argue that designing such transition path is in itself a new potential role for the Design in the diffusion of sustainable systems innovations.

PSS does not ensure by itself an effective improvement on the environmental performance of a given system. Detailed investigations are necessary during the design phase, evaluating issues such as possible rebound effects, impacts on the tangible and intangible values of consumption and approaches to risks reduction (TUKKER, 2004), and the connection of PSS with convergent approaches such as social innovations, sufficiency, leapfrog, crowd-design, cradle-to-cradle and distributed economy. The present paper focuses on this last issue as detailed on the next section. 


\subsection{The distributed economy concept}

The process of shifting satisfaction from the acquisition of physical artefacts to the acquisition of a package of products and services offers an opportunity to re-design the relationship among businesses. This assumption has lead to the main research question tackled on this paper: can a PSS be a driver to achieve a distributed economy? Conventionally a distributed economy can be seen as a transformation in the industrial system, moving away from the socioeconomically and environmentally unsustainable dynamics associated with large scale, centralized production (JOHANSSON; KISH; MIRATA, 2005). Some of the key characteristics of a distributed economy are:

- Focus on local production: according to Johansson, Kish and Mirata (2005) and Meroni (2006) most activities throughout the value chain, from conceptual design to product disposal, remains dominantly local. Kisch (2006) argues that it is design and knowledge that travels on such environments (KISCH, 2006). Whatever cannot be produced locally is exchanged and shared, giving rise to a society and an economy that is at the same time both local and cosmopolitan (MANZINI; MOJOLI, 2006);

- Focus on small, decentralized and flexible production units: these entities are more flexible and agile to respond to local market needs and, therefore, they can generate a bigger innovation drive (JOHANSSON; KISH; MIRATA, 2005);

- Synergistic connection among production units; according to Meroni (2006) a distributed economy facilitates the achievement of self-sustainability of local initiatives, facilitating their networking with similar activities and with the production and consumption systems of reference. Manzini and Mojoli (2006) calls attention that a distributed economy is not the adaptation of central systems to peripheral circumstances, but rather a global network of alternative initiatives with common characteristics;

- High level of customization to local requirements: proximity of between producers and final users reduces the trade-off between customization and cost/ speed, reducing the ubiquity of identical products. Standardization is one possible strategy to reduce costs on a distributed economy but by adopting such strategy potential local opportunities might be overlooked and the solutions might be poorly integrated into the local environment, resulting in its failure. Thus, as pointed by Tsvetkova and Gustafsson (2012), customization is required for industrial ecosystems to be adjusted to local conditions efficiently.
Johansson, Kish and Mirata (2005) argue that on "distributed economies" different innovative development strategies can be pursued in different regions. The same authors argue that similar or complementary schemes can be integrated on such economies to provide the advantage of scale without the drawbacks of inflexibility. Hence, on this alternative view, a distributed economy requires a balance between large and small-scale production.

Distributed economy clearly is not an entire new concept. Some of its key characteristics can be traced on pre-industrial economies, such as production on small batches (due to artisanship) and high production flexibility (due to limited division of labour). However, the advent of communication and information technology is a considerable drift from those early production paradigms. Whilst communication back then was limited to direct conversation between people living on neighbour villages, nowadays there is an almost instantaneous flow of knowledge, as well as cultural diffusion, across the globe. ICT technologies are enabling implementation of small scale production facilities, including fabrication on the household itself through rapid prototyping technologies. Hence, by promoting a distributed economy it is plausible to expect a drastic reduction on the resources employed on logistics systems.

\section{Research method}

This research was conducted on a period of five years, using Multiple Case Studies from different business sectors: (i) Automotive industry, (ii) Office space provider and (iii) Pipes and fitting manufacturer industry. The main criteria to select these case studies was firstly their interest on exploring a shift in the focus of their business processes from selling/acquiring physical artefacts to selling/acquiring a package of products and services that could jointly fulfil specific satisfaction requirements. Secondly there was an intent of getting examples of the three main typologies of PSS (service-oriented, product-oriented and resultoriented).

The research involved initially a review on the state of the art of PSS, focusing mostly on the methods to effectively design a PSS (see Figure 1). In general terms the field study has adopted the Methodology for Product Service System (MEPSS) proposed by Van Halen, Vezzoli and Wimmer (2005). MEPSS has integrated a set of tools developed on an European consortium involving universities and consulting companies. According to Van Halen, Vezzoli and Wimmer (2005), the main goal of MEPSS is to develop new PSS aligned with the goals of the company's business, offering high quality of service for the consumers and, at the same time, minimizing negative impacts on the environment. The entire framework consists of five main phases (VAN HALEN; VEZZOLI; WIMMER, 2005): "strategic analysis", "exploring opportunities", 


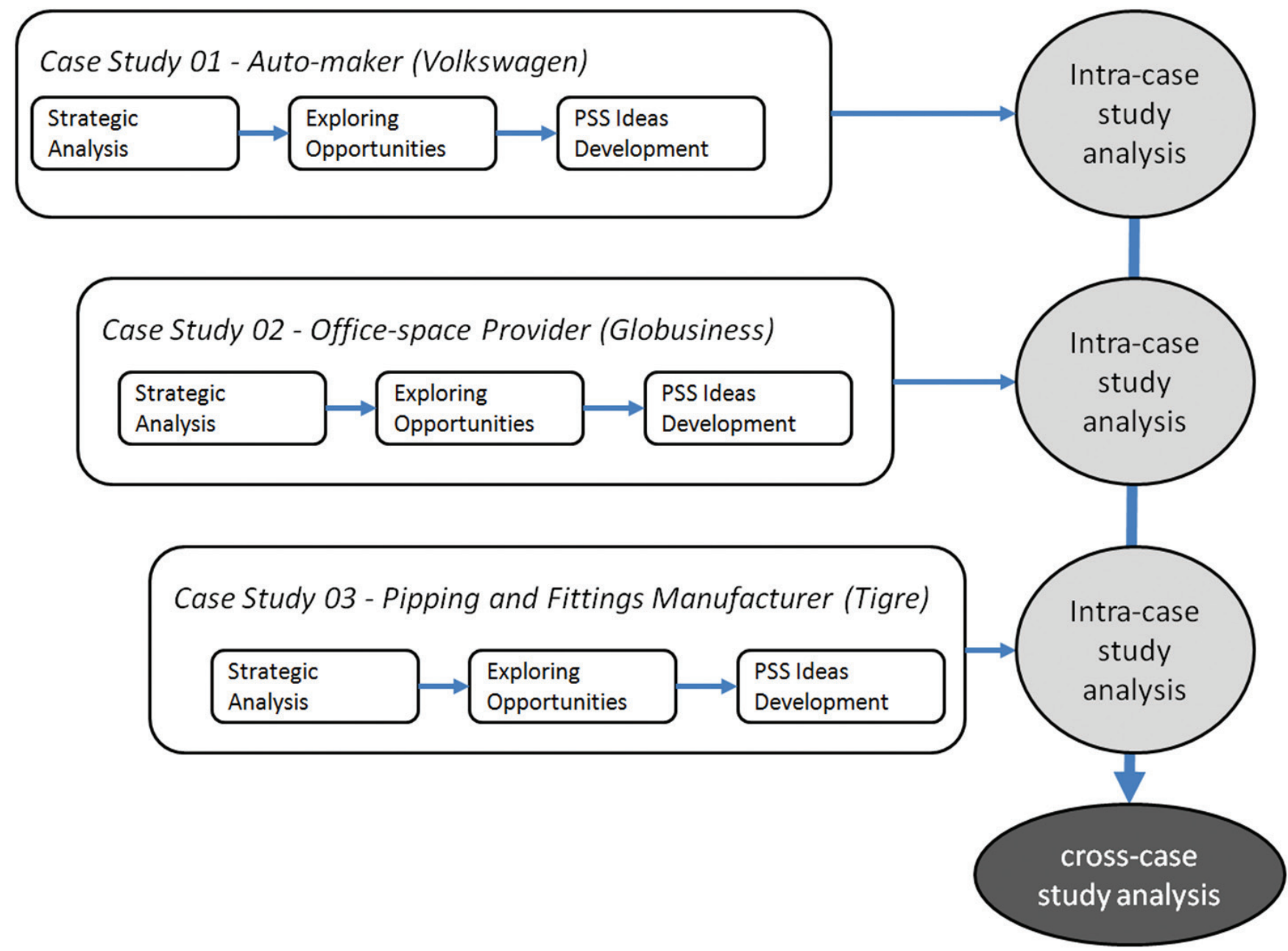

Figure 1. An Overall view of the Analytical Strategy of this Research.

"PSS ideas development", "PSS concept Design" and "Development and Implementation". Each of these phases is divided into steps, which are in turn subdivided into processes.

On the present paper it is reported the results obtained on the case studies after applying the initial three steps of MEPSS. The analysis occurred in two stages: each case study was individually analyzed and subsequently a cross case study analysis looked for recurrent patterns across these case studies. The analysis has focused on key principles of a "distributed economy" as presented by Johansson, Kish and Mirata (2005), Meroni (2006), Kisch (2006) and Manzini and Mojoli (2006): "focus on local production", "focus on small, decentralized and flexible production units", "synergistic connection among production units", "hhigh level of customization to local requirements".

The data collection protocol followed the propositions of Van Halen, Vezzoli and Wimmer (2005) for a methodology for PSS Design. The Strategic Analysis phase, for instance, aimed to understand the system in use by the company to meet customers satisfaction. In order to achieve this goal it involved semi-structured interviews, system maps, SDO-MEPSS (Sustainability Orienting Toolkit), direct observation, photography and document analysis. The function of each tool is explained in the Table 1. On Case Study 01, due to the need of a more quantitative analysis required by the project partners, the study has used the SimaPro software to perform the LCA analysis on this phase.

The "Exploring Opportunities phase" aimed at exploring new possible scenarios for the system. It was performed with the participation of the stakeholders involved in the process. In order to provoke reflections, stimulate creativity and help to change conventional paradigms on production/ consumption practices, the researchers presented cases on PSS for the participants, all gathered from the Eco.Cathedra databank. This databank was developed by Politecnico de Milano, and is used as a tool to collect and exchange cases and guidelines on Design for Sustainability (VEZZOLI; SCIAMA, 2007; LENS-POLIMI, 2013). 
Table 1. Range of tools adopted on the Strategic Analysis phase.

\begin{tabular}{|l|l|}
\hline \multicolumn{1}{|c|}{ Tool } & \multicolumn{1}{c|}{ Function } \\
\hline Semi-structured interviews & $\begin{array}{l}\text { Relevant information about the dynamics of company operations, processes and products/processes, } \\
\text { environmental policies and the decision making process. }\end{array}$ \\
\hline System maps & $\begin{array}{l}\text { Mapping the flow of material, information, information and work on the current product-service system, including } \\
\text { the flow with and between key stakeholders. }\end{array}$ \\
\hline SDO-MEPSS & Qualitative assessment of the current system performance in all dimensions of sustainability. \\
\hline Direct observation & $\begin{array}{l}\text { Carried out using annotations (texts and drawings) of each step of the current system/business process, including } \\
\text { relevant information that could be useful in the system map and SDO-MEPSS, as well as insights for possible } \\
\text { solutions. }\end{array}$ \\
\hline Photography & $\begin{array}{l}\text { Registered the main steps of the current process, including relevant information that could validate information } \\
\text { gathered on the other techniques }\end{array}$ \\
\hline Document analysis & $\begin{array}{l}\text { Information about the company operations, processes and products/services, environmental policies and decision } \\
\text { making process. }\end{array}$ \\
\hline
\end{tabular}

Tools such as System Map, Storyboards, Polarity Diagram and SDO-MEPSS contribute to visualize and describe the implications of the evolving ideas. The data on this phase was collected through diaries, digital recording and photography. The information collect and analysis was performed by visual and descriptive tools, for example: System Map, Storyboards, and Polarity Diagram, and SDOMEPSS checklist. This phase results on a set of scenarios for PSS, each of them with qualitative assessment about their implications on sustainability, exploring untapped opportunities and linking them with the company's business strategy.

On the "PSS ideas development" phase the main task is to shape in more depth the most promising PSS ideas. On the field study this phase have a more intense involvement of the stakeholders, with discussion on the proposals and subsequent suggestions for further improvement. The discussions focused on issues such as the satisfaction unit, the level of interaction with the client on each PSS concept, the operational and strategic implications of adding new stakeholders on the system, the PSS boundaries and the required transitions from the current system to the envisioned PSS. The result of this collaborative assessment was a qualitative assessment on the feasibility of the PSS concepts.

\section{A Result-Oriented PSS: Case study at Volkswagen}

\subsection{The context}

This case study was carried out between 2006 and 2008 and explored the concept of PSS on the packaging systems of components used to protect the chassis during the painting process (SAMPAIO, 2008) (MSc dissertation written in Portuguese). The business partners on this pilot project involved Embrart (packaging manufacturer) and Volkswagen. At the time of the research project Embrart was a major packaging manufacturer in the State of Paraná and Volkswagen was second in the country in terms of sales. It had three manufacturing plants located in Brazil, two of them producing cars and one plant dedicated to producing trucks and buses. The unit studied was located in the Metropolitan Region of Curitiba, and produced three models of passenger cars in its production line.

\subsection{The problem}

The study focused on the packaging used to transport materials for the waterproofing process. An average of $600 \mathrm{~kg}$ of cardboard packaging was disposed every month; it also consumed $50 \mathrm{~kg}$ of plastic film on the pallets that transported the cardboard boxes. They were used to transport plastic components used as temporary sealing of holes located at the bottom of the chassis (see Figure 2a, $2 b$ and $2 \mathrm{c}$ ). The process used a variety of sealing components (28) and four different types of cardboard packages.

The company needed an innovative solution for the provision of packaging that went beyond conventional practices. The drivers for such necessity were requirements on State and Federal laws, as well as compliance to ISO14001 standards (ASSOCIAÇÃO..., 1996), in order to maintain the certification of the Environmental Management System (EMS). The Paraná's state law Number 12493, 1999, defines that generators of solid waste, of any nature, are responsible by their packaging, storage, collection, transport, treatment and final disposal. ISO 14001 requirements includes environmental policy, with the setting of goals and environmental performance commitments of the company, which in this case focused on packaging. Worth mentioning that the packaging lifecycle management on this case study was performed only partially by the automaker, since there was a specialized recycling company that performed most of the process. 


\subsection{The opportunity for contributing to a distributed economy through PSS}

The transportation of the packaging was done for a relatively long distance (around $500 \mathrm{~km}$ ), bearing in mind the extremely light weight of sealing components, their low economic value and high volume. The transport was carried out through diesel trucks, resulting high environmental impact due to the use of non-renewable energy and the emission of toxic gases. Life Cycle Analysis (LCA) with SimaPro enabled to identify that the most significant environmental impact of the process was on the transport activities (about $67 \%$ of the overall impact) with packaging representing only $33 \%$ of this impact. Therefore, developing a local sealing manufacturer would have the most significant impact in environmental terms. Also, one of the challenges of the project was a more direct involvement of local manufacturers on the provision of packaging solutions. Such proximity between the packaging manufacturer and the automaker could result on further synergy and customization of solutions, which is line with the concept of distributed economy.

\subsection{PSS concept}

A workshop carried out with Volkswagen and Embrart, presented a diagnosis on the current packaging system and presented new scenarios focused on PSS concepts. This workshop used SDO diagrams, storyboards, system maps as well as the results of the Life Cycle Analysis carried out through Simapro.

The PSS concept selected by the companies representatives was a "Result Oriented" PSS, with the provision of "component protection" instead of selling packaging. In this concept the packaging manufacturer would adopt a returnable corrugated cardboard box (see Figure 3), which could be adopted for all types of sealing components, reducing the complexity of the logistics.

This PSS concept implies the adoption of a single supplier for all sealing components as well as a single supplier for the packaging process. Embrart would be responsible not only for providing the packaging itself but, very importantly, for managing its entire life cycle, including disposal. This concept would allow a significant reduction of environmental impacts due to packaging, mostly with the reduction on the transportation activities, with an estimated reduction of two hundred kilometres per cycle.

\subsection{Implications of the PSS concept to a distributed economy}

The main implications of this case study on the main attributes of a distributed economy are analyzed below:

- Focus on local production: there would be fewer players involved in the new system, and the life cycle management would be fully on the hands of the local stakeholder that had more competence on packaging technologies. However, on this concept Embrart
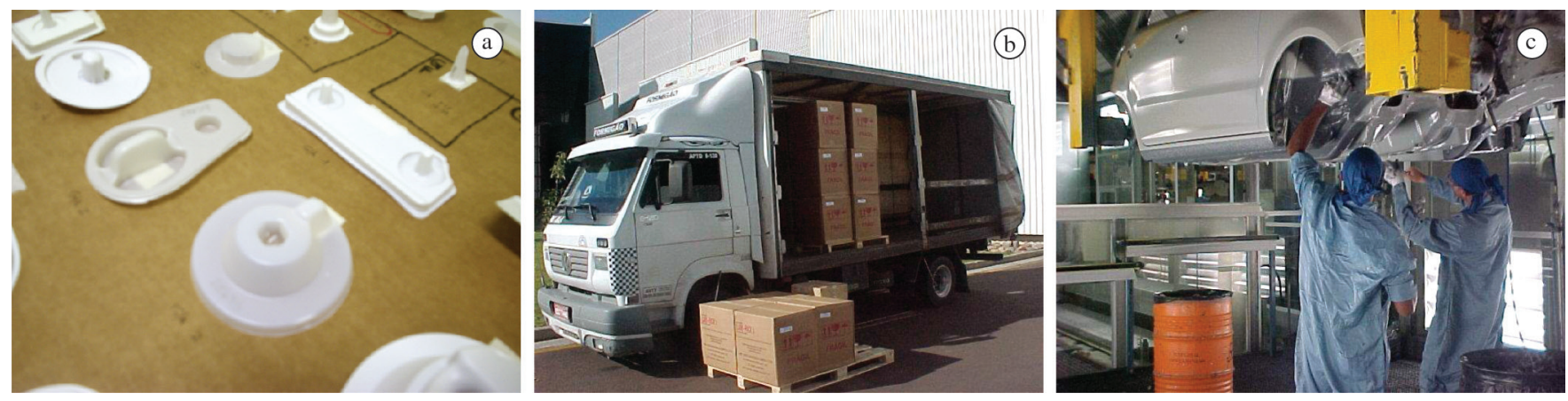

Figure 2. View of the process: a) sealing components b) delivery of packaging c) production line.


Figure 3. Storyboard of the proposed system, based on returnable packaging. 
would have to develop logistical competencies beyond its current practices;

- High level of customization to local requirements: the PSS would cause a small contribution on the improvement of operations on the factory floor. The pilot study unveiled contributions on the reduction of variability in production by reducing the possibility of missing some models of the sealing components during packaging. Indeed, the packaging supplier would be directly responsible to deliver sealing components with quality and on time on the assembling line;

- Synergistic connection among production units: the concept that derived from the creative process presents a dramatic change on the level of synergy between the automotive and the packaging manufacturer. However, at the same time it did not include any synergy with other automotive or packaging manufacturers established in the same region;

- Focus on small, decentralized and flexible production units: the packaging manufacturer had a large facility that centralized all production orders. Despite that, its closeness to the automotive maker enable higher flexibility to speed, volumes and Design requirements.

\subsection{Concept Evaluation}

The pilot study consisted of applying the concept on the flow of one batch of components delivered on the factory. Evaluation of the pilot study was demonstrated through LCA and, also, through payback analysis. In economic terms, it was estimated that the payback would occur after 20 cycles of using (about 10 months) the returnable packaging system. The pilot study demonstrated the environmental contribution due to the reduction of cardboard waste and, most importantly, a reduction in the distance travelled by packages.

However, although the Volkswagen representatives concluded that the proposal was viable in functional terms, with clear environmental benefits it was deemed uneconomical since it demanded a longer payback than those commonly practiced by the company (6 months). Most long term environmental costs were not externalized by their competitors and, therefore, cost reductions on this issue would bring reduced tangible competitive benefits for the business.

The demonstration of the positive environmental benefits of the new concept was not sufficient to motivate its full implementation. The main reason identified through nonstructured interviews was the fact that the project dealt with a non-critical component in terms of economical value. It confirms the importance of the economical impact as a receptivity attribute for PSS, as proposed Cook et al., (2006).
Brazilian laws and regulations lack on instruments that could effectively result on competitive economical advantage to companies intending to offer artefacts integrated with life cycle management services or even result-oriented solutions. The relatively small economical benefit of the PSS did not match the intensive managerial effort that would be required for implementing and maintain the system.

An important barrier for the adoption of PSS at Volkswagen was clearly the lack of knowledge and previous experiences on the theme in this particular area of the company. They had a good experience on co-designing products and components with their suppliers but very little experiences on co-designing services. Despite that, the organizational structure to implement PSS was mostly in place and could facilitate that, with the benefit of long lasting relationships with suppliers already in place.

\section{A Use-Oriented PSS: Case study at Globusiness}

\subsection{Context}

The second case study was carried out at Globusiness, from 2008 to 2010 and it is described in details in Silva (2010) (MSc dissertation written in Portuguese). This is a company specialized on providing "office space", a all-inclusive renting concept, with service packages that offer the possibility for customers to rent offices that are fully equipped with furniture, carpets, IT equipment, communication technology, lightning, among other issues. In line with Besch (2005) 's proposition, the renting contract adopted by the company has minimized the financial risk by establishing a minimum renting period. Their services target mostly corporate clients, with a mix of products and services that resemble a "Use Oriented PSS", with Globusiness retaining the ownership of the tangible products and receiving monthly payments. Globusiness was operating already seven years on the market of office-space provision. The services provided by the company could be customized according to client demands; the company also offered standardized packages of products/services, which could be arranged according to clients' needs. Contrary to Besch (2005) statement, they did accept such standardization as it resulted on reduced costs.

\subsection{The Problem}

The company did not take strategic advantage of their inherent contribution towards sustainability. The interviews have shown that environmental and social issues were not a concern on the client's requirements when choosing the company. Most of the flows (materials, information, financial, work) observed while developing the system map (see Figure 4) related to everyday services demanded by the clients (E.g.: IT technical assistance, telephone 


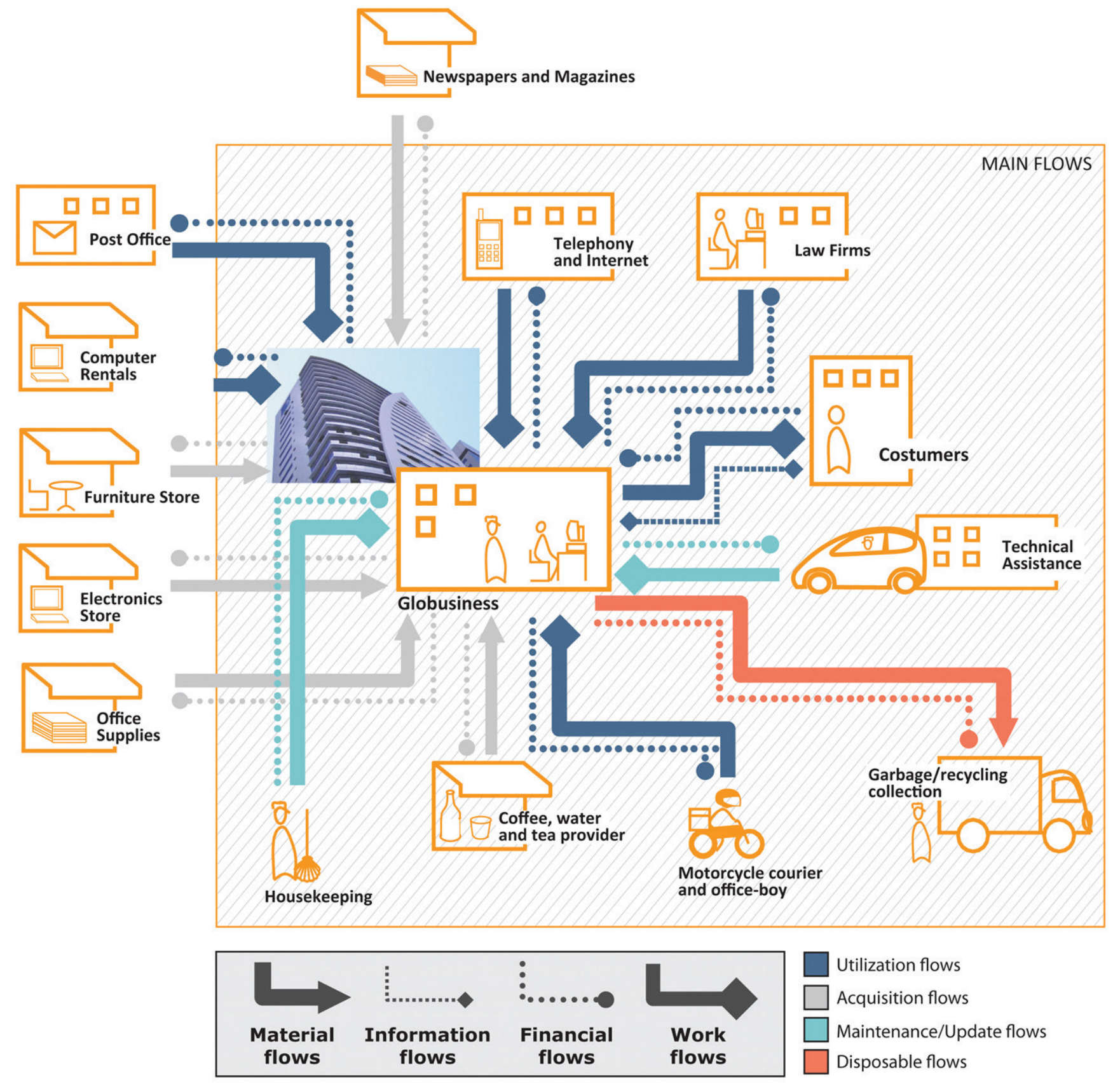

Figure 4. Globusiness system map previous to the study.

and internet services). The flows associated with the more durable artefacts (e.g.: furniture, computers) did not included life cycle management services and their product concepts did not employ life time extension strategies, a similar finding on the study of Besch (2005) on furniture leasing and renting.

The system dynamics at Globusiness showed great potential to enhance its level of environmental performance. The system already resulted in environmental and economical advantages when compared to conventional forms for acquiring office facilities. The intrinsic environmental benefit of the business occurred due to the optimization of product life cycles and the avoidance of product acquisition by their customers. However, the observations showed that it operated at sub-optimal level regarding environmental performance, not presenting some of the practices proposed by UNEP (UNITED..., 2002) on service-oriented PSS such as maximization on the amount of shared products, 
extension of product life cycle and use of technological features and economies of scale that result on higher level of eco-efficiency.

The assessment of its environmental performance through the SDO tool confirmed that eco-efficiency was not a priority in the existing PSS. Moving the company on this direction faced the challenge of reduced competencies of their personnel on issues related to sustainability. The directors at Globusiness reported that have never engaged on co-design of products with their suppliers neither have ever properly designed their services and this factor configure a barrier expand its relationship with local stakeholders. Developing such competencies would be critical do implement improvements such as an integrated waste management or designing a furniture platform focused on Design for Sustainability principles.

\subsection{The opportunity for contributing to a distributed economy through PSS}

The diagnosis carried out on the company showed that it had a good relationship with customers, offering personalized services and attending promptly their individual demands. On the other hand the relationship with other stakeholders (see system map on the next figure) presented lesser proximity, not going beyond commercial transactions and with a short term perspective. Bringing their local stakeholders as true partners to their PSS configured an opportunity to enhance their sustainability performance, with direct contributions to achieve a more distributed economy. The PSS proposition implied the integration of environmental sustainability on the strategy of the company in order to bring effective competitive advantage. The company understood and committed itself to perform a review of its strategy, including medium term targets for improving its environmental performance. Moving the company on this direction faced the challenge of reduced competencies of their personnel on issues related to sustainability. The directors at Globusiness reported that have never engaged on joint projects with their suppliers to improve their products and neither have formally designed their services in collaboration with other stakeholders.

\subsection{PSS concept}

Two workshops were carried out in order to devise the proposition of interventions on the current system. The first workshop involved solely the research team and focused on analysing the data gathered in the company and compares the status of their PSS with benchmark examples available at the Eco.Cathedra database. The second workshop was carried out within the company and initially it involved a presentation and discussion on the environmental performance of the current system, including the main findings obtained on the first workshop. At the end of this workshop a creativity section took place, using brainstorming, storyboards and system maps as supporting tools.

The evaluation criteria for selecting ideas on the second workshop were "feasibility of implementation", "impact on competitiveness" and "extent of environmental benefits". The company directors have chosen scenarios of PSS that were not radical on their essence but offer a smooth transition on the business process. The system map illustrated on Figure 5 represents the result of the revised PSS, now including eco-efficiency as a central competitive issue. The detail shows the addition of bike transport and mobility services as an example of the implications of the new PSS in expanding the network of partners.

On this PSS concept the main issue is to raise the level of eco-efficiency at Globusiness centred on the strategy of establishing long term partnerships with key stakeholders in order to implement life cycle management practices (Figure 5). Flows of materials are now more integrated and interconnected; waste management providers are brought onto the system; stronger emphasis is given on result-oriented suppliers. This new system anticipates a new relationship with the clients since their behaviour and habits interfere directly on the level of consumption of energy, water, paper and other resources. Information provided by the clients would be vital for enabling the monitoring flows throughout the system, thus allowing appropriate actions from an environmental perspective.

\subsection{Implications of the PSS concept to a distributed economy}

The main implications of this case study on the main attributes of a distributed economy are:

- Focus on local production: the concept expand and deepen the involvement of local stakeholder, resulting on a higher level of responsibilities on product life cycle management. As an example, the concept includes a partnership with an a local NGO for an appropriate destination of electronic equipment, which could include repair or disassembly, enabling them to raise funding for social initiatives or donation of the refurbished equipment to community institutions;

- High level of customization to local requirements: at the time of this research, there was a lack in the city of Curitiba of a public system to manage the life cycle of furniture that has been disposed. According to Hopfenbeck and Jasch (1995) the main environmental impact during the furniture life cycle is produced by the extraction of raw materials and the final disposal of furniture in the end of life. Hence, 


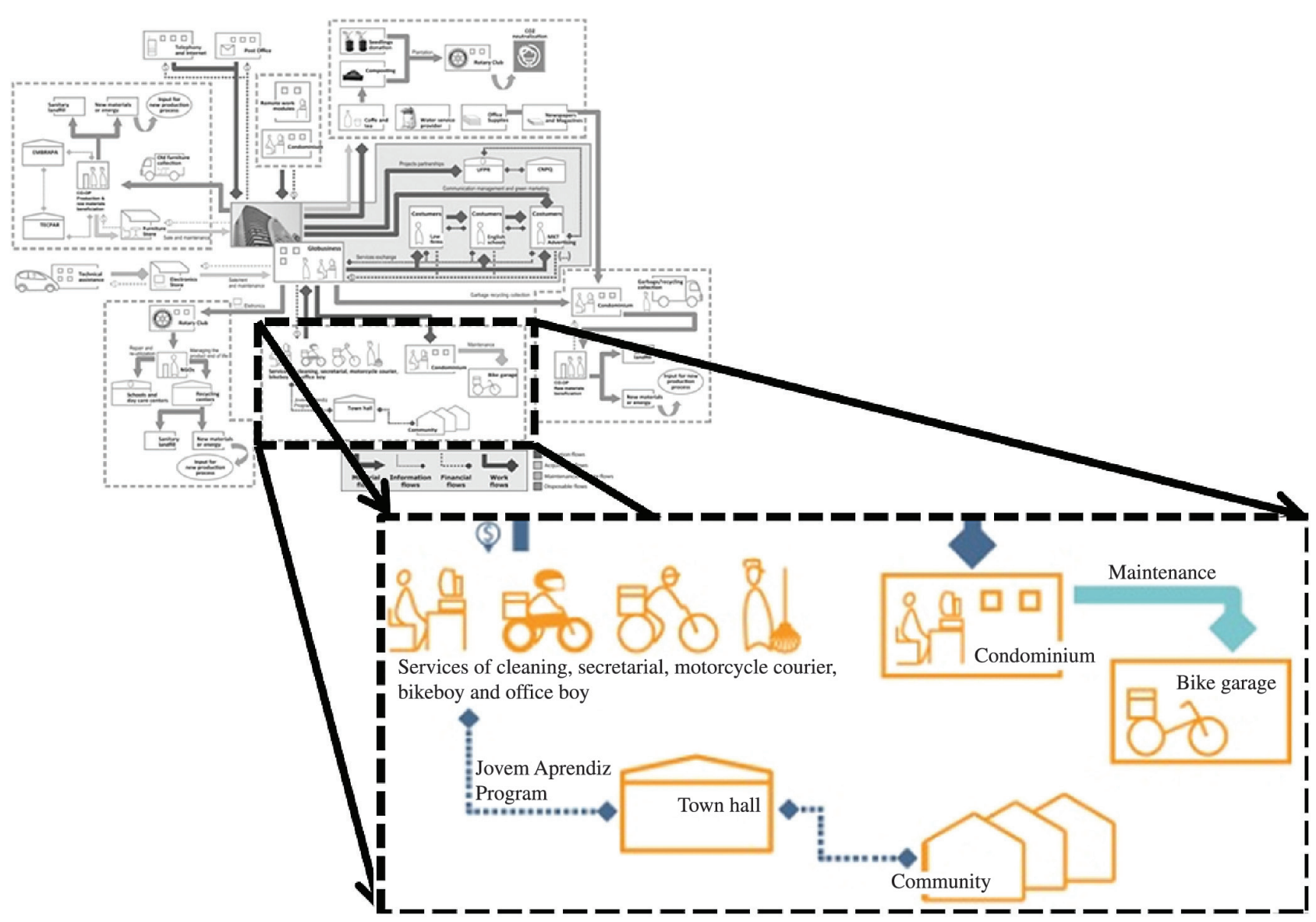

Figure 5. PSS concept - extending the network of partners.

one important player integrates the PSS concept: a local cooperative specialized in furniture repair, re-use, recycling or waste disposal. These local organizations have already found an economical balance that turned the revenue of sorting and disassembly furniture above the operations costs;

- Synergy among production units: the system that resulted from the creative process did not include any partnership with companies operating on the same business. However, a more collaborative relationship with the network of stakeholders could improve even further Globusiness environmental performance, which in turn could contribute to differentiate the company against its competitors;

- Focus on small, decentralized and flexible production units: the operations of Globusiness could be considered small and flexible but they were centrally managed throughout the entire business process.

\subsection{Concept evaluation}

The concept developed for Globusiness shift their environmental performance one step further, bringing the suppliers into the system to care for product life extension with aesthetic and functional upgrades/maintenance, reuse, recycling or waste disposal. Its implementation would put the company in line with the National Policy for Solid Waste, instituted by Federal Law $n^{\circ} 12.305$, which includes shared responsibility for the whole supply chain for the product life cycle.

However, like the Volkswagen case study, there was little externalization of environmental costs on the packaging market in Brazil and, thus, efforts to improve environmental performance of these artefacts would most certainly increase costs and reduce profitability. On the case of electronic equipment and appliances, for instance, the progressive reduction on the cost of acquisition has resulted on a situation where it is economically cheaper to buy a new product rather than to fix the existing one. Similarly to the legislative conditions in the EU (BESCH, 2005), it would be cheaper and easier to burn or dispose most old artefacts than to recycle it. Hence, the new concept would require a long term effort to develop cost effective suppliers and, most importantly, higher environmental performance had to be included on their marketing strategy in order to convert efforts on this direction into better competitiveness. 
Moving the relationships with stakeholders from mere commercial transactions to effective partnerships in a collaborative environment clearly was the toughest task that would be faced by the company on the implementation stage of the proposed PSS. Some of the suppliers were large companies with strong bargain power, where Globusiness alone would have a small likelihood of provoke relevant changes in their environmental practices. Implementing the concept would require, therefore, a wider articulation with other stakeholders in order to make the case economically interesting for all parties. The absence of a recognized institution (ex: union) that could effectively act as a platform for dialogue for the entire supply chain or even among competitors, add further complexity on this issue. Another bottleneck to achieve the desired close relationship with the supply chain was the lack of suppliers with offers associated with PSS concepts, particularly on furniture. Indeed, maintenance services throughout the life cycle or end-of-life services are offers still quite absent on the Brazilian furniture market.

\section{Product-Oriented PSS: Case study at Tigre}

\subsection{Context}

The third case study was carried out between 2010 and 2011 (See Costa Junior (2012)) - MSc dissertation written in Portuguese) in partnership with Tigre and funded by CAPES (Brazilian funding agency). Tigre is a major producer of piping products in South America and up until this research project they had no PSS offers on their portfolio. In Brazil their commercial transactions were carried out directly with small and large retailers throughout the country. The research project main goal was to develop a "Product Oriented PSS" for rainwater harvesting, aiming low-income households.

\subsection{Problem}

It was evident from the beginning of the project that although the provision of products was central to the Tigre's core business, the provision of services was also seen as important in their search for an "integrated solution" (product+services) in the case of rainwater collection. The company provided technical and consulting services for companies of the civil construction sector. Also, the company had since 1967 the Tigre Apprentice School (EATs), where it provided services for disseminating technical knowledge for civil construction professionals.

However, despite having products and services on their portfolio, the research team has not identified at Tigre a structured and systematic process for the design of services or packages of products+services. The research team concluded, therefore, that PSS constitute an innovation opportunity with wide implications for the company and its network of suppliers and partners. On this context, from the perspective of the company this project offered the added benefit of trying out and improves their understanding about the design process of a PSS, enabling the development of in-house competencies.

Sustainability permeates all company documents and strategy. Most of its initiatives were guided or imposed by environmental regulations. With respect to waste management and rational use of resources, the company implemented procedures in order to achieve better environmental performances; initiatives derived from ISO 9001 and ISO 14000 requirements. However, it still had not established a take back system, a demand present on the Federal Law $n^{\circ} 12.305$, which brought the manufacturers to share responsibility for the whole product life cycle. There was also a smaller amount of specific actions on corporate social responsibility, mainly addressed to their own employees.

\subsection{The opportunity for contributing to a distributed economy through PSS}

Due to the continental scale of the company the research team expected from the outset that the PSS would push the company to partner with local stakeholders, thus having access to strategic complementary infrastructure and competencies, enabling an agile response to user demands. The relationship of the company with user was also another area where there were great expectations of change. Their commercial transaction with final users occurred mostly through wholesale (B2B). Although there was great interest in the company to have a more close involvement of the end user in the process of product development, this practice still represented something new in the corporate structure and culture. Indeed, the system map carried out on the workshops about the current system unveiled a lack of direct communication with final users.

\subsection{PSS concept}

The PSS development process on this case study adopted a stage-gate approach, following the phases proposed by Van Halen, Vezzoli and Wimmer (2005): "strategic analysis", "exploring opportunities", "PSS ideas development", "PSS concept Design" and "Development and Implementation". Each of these phases involved the development of workshops at the company and university, alternately. The original intent of the researchers on this project was to develop a "Result Oriented PSS" where the user would pay-per-use cubic meters of rainwater. However, right from the outset it was clear that such system would demand personnel and structure that the company was not 
prepared to develop on the short term due to the continental scale of its operations.

Consumers (low income families) would obtain ownership of the product (rainwater harvesting) and the company and its partners would provide additional services throughout its life cycle. This "Product-oriented PSS" was not a complete rupture from its existing business process, which could offer a smooth transition towards other forms of PSS. The concept did not demand a radical change on the company structure and competencies neither an expansion on the number of stakeholders to be dealt daily by the company, once the PSS was implemented. The changes and improvements that would be required on the PSS would help preparing the company for new regulation and legislation in Brazil which are now increasing the responsibility of manufacturing industry regarding the end of product life cycle.

The product for rainwater harvesting involved thirteen innovations that are now on the process for obtaining patent and, because of that, cannot be described on this paper due to a confidentiality contract. Seven services could be offered in combination with the product, as listed below.

- Maintenance: services related to cleaning of reservoirs and possible repairs and parts replacements;

- Monitoring of Water Quality: inspection service to ensure the user water quality determined by legislation;

- Information Centre: information service about the benefits of rainwater collection and provision of feedback to questions relating to the products/ services offered;

- Distance Learning/Itinerant Learning: remote teaching on technical issues such as installation, maintenance, disposal and operation of a system of rainwater collection, including issues related to its economic, environmental and social implications;

- Flood Monitoring: the product could capture information in real time about rainwater flow, providing information to institutions such as civil defence and fire department about the risk of flooding;

- Micro-credit: partnerships with banks and financial institutions to enable access to the PSS to the very poor;

- Carbon Offset: each rainwater litre collected could be converted into points that subsequently could be used by the user as discounts on "eco" products/ services that contribute to reduce water consumption.

Two of these services followed to the next stage of the project, with detailing and pilot implementation. One of them was the Information Centre, which should provide to final users access general information about the product and its environmental implications. This service provides key information that enables the user to perform maintenance, installation and disposal of the product. It offered information that allowed the user to contract third parties to perform the maintenance, installation and disposal of the product. The user have access to four different channels of information: Web Portal, Phone Support, and Direct Mail and Paper based Manuals. This service was seen as viable because most of the families did have a Smartphone or a $\mathrm{PC}$ with access to internet.

The other service consisted of an "On-the-road Learning": a trailer that travels across the country providing service guidance on various issues related to collecting rainwater, including installation, maintenance, disposal and operation of a system of rainwater collection. This service is also intended to support community initiatives within government housing programs aiming low income families.

\subsection{Implications of the PSS concept to a distributed economy}

The main implications of this case study on the main attributes of a distributed economy are:

- Focus on local production: the PSS concept that has been selected by the company allowed local companies, certified after a basic training, to perform the maintenance, installation and disposal of the product for rainwater harvesting;

- High level of customization to local requirements: the complex nature of implementing rainwater harvesting systems on households that often are design and built by the low income families themselves demanded a high level of customization from Tigre;

- Synergy among production units: the concept anticipated direct collaboration only downstream the supply chain (service providers for maintenance, recycling and disposal);

- Focus on small, decentralized and flexible production units: these characteristics could be seen solely on the local companies that would be required to provide life cycle management services beyond the capability of Tigre. Production and distribution remained centralized as well a most of the services that integrate the PSS concept.

\subsection{Concept evaluation}

The process of evaluation the concept involved people that represent the target users. An artificial environment simulated the conditions of retail, attempting to bring the user experience closer to the reality. The evaluation included issues such as the experience of contracting the PSS, the usage phase, maintenance, installation and disposal of the product. The process consisted in testing the overall customer journey (service experience) using available 
volumetric model, mock-ups, illustrative images, folders, product samples, adverting materials interactive online software of the rainwater collector. Several visual cards with storyboards provided support to specific questions on the main touch points of the service experience. These cards represented key situations that the user could face during the interaction with the PSS.

The evaluation resulted on the agreement of the user with most of the concept. The form and aesthetics of the product has shown compliance with the expectations of all users consulted. The users with lower formal education had a certain degree of difficulty to understand its process for installation and maintenance, suggesting various improvements with impact on the cognitive aspects of the product. The suggestions for improving the service side of the PSS included issues such as avoidance of a robot on the other side of the line on the Information Centre, a more intensive use of visual communication and provision of further information throughout the service regarding the cost benefits of the system. After this evaluation a revised version of the services was presented to the company and approved for implementation on a pilot scale. Further research will be carried out in order to assess the robustness of the concept during the real world implementation.

\section{Lessons learnt}

In general terms all PSS concepts involved an expansion on the amount of stakeholders, most of them locally based, which is in line with one of the key pillars of a distributed economy. Such expansion on the net of stakeholders was motivated by risk reduction and the need of rapid implementation of infrastructure and life cycle management competencies required by the PSS. However, opening up the company to a broader set of local partners might find on the geographical scale of the operations an inhibitor factor. In the case of Case Study 03, where the company operated in the entire South America, the selected PSS consider the involvement of local stakeholders solely to a limited set of activities, maintaining centralized all production activities. Such decision was clearly influenced by the perception of higher complexity of managing a PSS, already pointed by UNEP (UNITED..., 2002) as a major barrier for its adoption within businesses. Despite such benefit, Case Study 01 have shown that PSS can lead to a reduction on the number of local players required to provide satisfaction to the client, particularly on result-oriented approaches, where there is a demand for more close relationships between the client and PSS supplier.

The client-supplier proximity that characterizes a PSS drives and facilitates the provision of customized solutions, i.e., solutions that are more closely linked to what the client effectively requires. In Case Study 01 these particular requirements came from the factory floor and related to the reduction of mistakes in logistics. Customization on that case resulted on higher responsibilities for the service provider but it was an easier task due to the more stable nature of the manufacturing process and the Business-toBusiness relationships. Achieving such customization on Case Study 03 presented itself as a much more complex challenge since each house on the same neighbourhood might present a totally different requirement for installing and maintaining the rainwater harvesting.

All case studies showed an absence of efforts to develop synergy connections among similar production units, particularly with direct competitors. The concepts anticipated direct collaboration mostly with stakeholders downstream the supply chain, particularly with service providers for maintenance, recycling and disposal. Cooperation with similar production units could result on a more dramatic minimization of resource usage as well as reduction of costs and amount of effort to implement the PSS. In Case Study 01 and 02, for instance, the absence of cooperation with other companies on the same market hindered the implementation of key actions to implement a PSS: a milk run logistics (a strategy based on round trips that facilitates both distribution and collection) and an effective system for managing product recycling/disposal.

Another pattern observed on these case studies is that a PSS does not necessarily leads to the adoption of small, decentralized and flexible production units. In Case Study 01, for instance, a group of small companies would have difficulties on offering a full range of services (design, production, distribution, life cycle management) on the scale required by Volkswagen. Embrart, a medium size company, had the organization capabilities for such venture. It was quite motivated to implement the PSS, although it was prepared to implement a limited scope of innovations. Heiskanen and Jalas (2003) speculate that on situations where companies deliver results, they might not be committed to specific technologies, making them more flexible and innovative. On this study that was not confirmed since the packaging manufacturer insisted on continuing the use of cardboard on the packages, though the PSS demanded a more durable and reusable solution. The argument for that decision was that the PSS proposal would represent a very small share of the overall business and maintaining the existing technology would make a transition towards this new business process more viable in organizational terms.

The case studies have shown that PSS can drive higher flexibility into the business process. Notwithstanding, the characteristics of the artefacts and its production processes can limit the level of flexibility achieved by a PSS. In Case Study 02, for instance, the use of fixed location for providing office facilities have overcome the bulky and heavy nature of furniture, which is pointed by Besch (2005) as a barrier for use-oriented services associated with furniture. This fixed 
location implied on higher costs with mobility for clients and, therefore, affected their decision regarding the renewal of contract. In Case Study 3 (product-oriented) the nature of the production technology demanded a higher level of quality control over production, resulting on the decision of the company to maintain production centralized, integrating local stakeholders solely on the life cycle management services.

Very importantly, none of the companies that took part on the Case Studies presented formally the intent of contributing to sustainability through a distributed economy. Motivations for adopting a PSS ranged from marketing to efficiency in production. In Case Study 03 the assessment was that the implementation of the PSS would bring direct economical benefits through spontaneous media. Also, company personnel involved on the research declared that they perceive the development of a PSS as valid strategy to strengthen the company's relationships with its users/clients by conveying a higher perceived value when compared to selling pure products. They perceived it as a potential market differential, especially due to the commoditization of many products on their portfolio.

\section{Conclusion}

The paper reports case studies in the main PSS categories (result-oriented, service-oriented and product-oriented) and the result showed that it is not possible to establish PSS as a strategy that could drive companies towards a "distributed economy". The authors have investigated the issue from a business point of view, involving both large, middle and small enterprises and the paper reports the results obtained on the initial three phases of Van Halen, Vezzoli and Wimmer (2005) methodology for PSS development: "strategic analysis", "exploring opportunities" and "PSS ideas development". The field research unveiled a potential contribution of PSS to expand the involvement of local stakeholders and on the achievement of a high level of customization to local requirements. This is true particularly regarding the involvement of service providers that contribute to life cycle management. On the other hand, the research have shown that it is not possible to say that a PSS can result on small, decentralized and flexible production units since some of the case studies pointed in complete different direction. Finally, although collaboration between companies on the same sector of the economy seems to be coherent strategy to enable the scaling up of a PSS, none of the case studies have shown an explicit intent on searching for such synergy. On this issue, policies aiming at promoting PSS within businesses need to consider the possibility of implementing platforms for supply chain collaboration prior to the promotion of PSS.

\section{References}

ASSOCIAÇÃO BRASILEIRA DE NORMAS TÉCNICAS - ABNT. NBR ISO 14001: environmental management systems: specifications and guidelines for use. Rio de Janeiro: ABNT, 1996. 14 p.

$\mathrm{BESCH}, \mathrm{K}$. Product-service systems for office furniture: barriers and opportunities on the European market. Journal of Cleaner Production, v. 13, n. 10-11, p. 1083-1094, 2005. http://dx.doi.org/10.1016/j.jclepro.2004.12.003

BRASIL. Ministério do Meio Ambiente. Action Plan for Sustainable Production and Consumption: SPC. Brasília, 2011.

COOK, M. B. et al. The transfer and application of Product Service Systems: from academia to UK manufacturing firms. Journal of Cleaner Production, v. 14, n. 17, p. 14551465, 2006. http://dx.doi.org/10.1016/j.jclepro.2006.01.018

COSTA JUNIOR, J. Proposition of a reference model for eco-efficient service design in product-service systems. 2012. Dissertação (Mestrado)-Federal University of Paraná, Curitiba, 2012.

GIARINI, O.; STAHEL, W. R. The limits to certainty: facing risks in the new service economy. Dordrecht: Kluwer Academic Publishers, 1989.

HEISKANEN, E.; JALAS, M. Can services lead to radical eco-efficiency improvements? A review of the debate and evidence. Corporate Social Responsibility and Environmental Management, v. 10, n. 4, p. 186-198, 2003. http://dx.doi.org/10.1002/csr.46

HOPFENBECK, W.; JASCH, C. Eco Design: environmentallyOriented Product Policy. Landsberg: Verlag Moderne Industrie, 1995. PMid:7617820.

JOHANSSON, A.; KISCH, P.; MIRATA, M. Distributed economies: a new engine for innovation. Journal of Cleaner Production, v. 13, n. 10-11, p. 971-979, 2005. http://dx.doi.org/10.1016/j.jclepro.2004.12.015

$\mathrm{KISCH}, \mathrm{P}$. Unleashing the true potential of being local: towards distributed economies. In: INTERNATIONAL SEMINAR: SLOW+DESIGN. Slow approach to distributed economy and sustainable sensoriality, 2006, Milan.

LENS-POLIMI. Education support tools. Available from: <http://www.lens.polimi.it/index. php?M1 $=6 \& \mathrm{M}=3 \& \mathrm{LR}=1 \& \mathrm{P}=$ tools_select.php $>$. Access in: 19 July 2013.

MANZINI, E.; MOJOLI, G. Manifesto: slow approach to distributed economy and sustainable sensoriality. In: INTERNATIONAL SEMINAR: SLOW+DESIGN, 2006, Milan.

MERONI, A. The valorisation of local resources and distributed economy. In: INTERNATIONAL SEMINAR: SLOW+DESIGN. Slow approach to distributed economy and sustainable sensoriality, 2006, Milan. 
MONT, O.; LINDHQVIST, T. The role of public policy in advancement of product service systems. Journal of Cleaner Production, v. 11, n. 8, p. 905-914, 2003. http:// dx.doi.org/10.1016/S0959-6526(02)00152-X

MONT, O. Clarifying the concept of product-service system. Journal of Cleaner Production, v. 10, n. 3, p. 237-245, 2002. http://dx.doi.org/10.1016/S0959-6526(01)00039-7

POL, E.; VILLE, S. Social innovation: buzz word or enduring term? The Journal of Socio-Economics, v. 38, n. 6, p. 878885, 2009. http://dx.doi.org/10.1016/j.socec.2009.02.011

SAMPAIO, C. P. Guidelines for designing corrugated cardboard packaging moved among companies based in product service systems. 2008. Dissertação (Mestrado)Federal University of Paraná, Curitiba, 2008.

SCHÄFER, M.; JAEGER-ERBEN, M.; SANTOS, A. Leapfrogging to sustainable consumption? An explorative survey of consumption habits and orientations in Southern Brazil. Journal of Consumer Policy, v. 34, n. 1, p. 175196, 2011. http://dx.doi.org/10.1007/s10603-010-9150-5

SCHMIDT-BLEEK, F. 1993. MIPS: a universal ecological measure? Fresenius Environmental Bulletin, v. 2, n. 6, p. 306-311.

SILVA, J. S. G. Guidelines for designing product-service systems for remote work. 2010. 225 f. Dissertação (Mestrado em Design)-Federal University of Paraná, Curitiba.

STOUGHTON, M. et al. The business case for EPR: a feasibility study for developing a decision-support tool. Boston: Tellus Institute, 1998.
TSVETKOVA, A.; GUSTAFSSON, M. Business models for industrial ecosystems: a modular approach. Journal of Cleaner Production, v. 29-30, p. 246-254, 2012. http:// dx.doi.org/10.1016/j.jclepro.2012.01.017

TUKKER, A. Eight types of product service system: eight ways to sustainability? Experiences from SusProNet. Business Strategy and the Environment, v. 13, n. 4, p. 246-260, 2004. http://dx.doi.org/10.1002/bse.414

U N I T E D N ATION S EN VIRONMENT PROGRAMME - UNEP. Division of Technology Industry and Economics - DTIE. Product-service systems and sustainability: opportunities for sustainable solutions. Paris, 2002. Available from: <www.uneptie.org/pc/sustain/reports/ pss/ pss-imp-7.pdf>.

VAN HALEN, C.; VEZZOLI, C.; WIMMER, R. Methodology for product service system innovation: how to implement clean, clever and competitive strategies in European industries. Assen: Royal Van Gorcum, 2005.

VEZZOLI, C.; SCIAMA, D. Experimental educational networking on open research issues: Studying PSS applicability and development in emerging contexts. International Journal of Sustainability in Higher Education, v. 8, n. 2, p. 198-209, 2007. http://dx.doi. org/10.1108/14676370710726652

VEZZOLI, C.; CESCHIN, F.; KEMP, R. Designing transition paths for the diffusion of sustainable system innovations: a new potential role for design in transition management? In: CHANGING THE CHANGE CONFERENCE, 2008, Torino. Torino: Allemandi Conference Press, 2008. 